\title{
MAXIMIZING THE VALUE OF RESIDENTIAL PROJECTS USING FUZZY RULE BASED LINEAR PROGRAMMING
}

\author{
Alp USTUNDAG, Emre CEVIKCAN \\ Industrial Engineering Department, Istanbul Technical University, \\ Istanbul, Macka 34367, Turkey
}

Received 28 Jul 2013; accepted 23 Oct 2013

\begin{abstract}
Optimizing the allocation of residence types has a great impact on efficient management of resources for construction projects. Hence, determining appropriate allocation of residence types provides effective financial activities, especially for large-scaled residential projects. Subjectivity and vagueness in the determination of price per $\mathrm{m}^{2}$ for residences requires the consideration of fuzzy logic, since the modeling of imprecise and qualitative knowledge, as well as the transmission and handling of uncertainty at various stages are possible through the use of fuzzy sets. This study proposes an approach that integrates Fuzzy Rule Based System (FRBS) with mathematical programming. In the proposed hybrid approach, FRBS is used to set price per square meter and it provides input for Net Present Value (NPV) formulation. Mixed integer linear programming (MILP) model is developed for the maximization of (NPV) of the project. The proposed model is applied to a residential project in Istanbul to demonstrate its performance. The optimal NPVs and allocation results for four types of residences are analyzed depending on the different factor levels of total construction area, sales rate and bank loan interest rate. The results indicate that the optimal NPV and allocation of residences are significantly influenced by the factor of construction area.
\end{abstract}

Keywords: residential projects, net present value, mixed integer linear programming, fuzzy rule based systems.

\section{Introduction}

The supply of residences can be regarded as a critical stage in construction projects under changing market conditions. Different types of residences in terms of size are presented by construction companies to their costumers so as to obtain marketing flexibility. Accuracy in the number and variety of residences supply provides convenience for financial planning to raise the cash necessary for investment and operations. Over-supply of residences lead to several problems such as increased production and inventory carrying costs. On the other hand, inadequate supply of residences leads to a different set of problems such as stock-outs and lost sales. The optimization of allocation among residence types prevents the detrimental impact of inaccurate supply.

Financial assessment of construction projects has been a critical problem since construction sector is an industry with high cost, high profit, and high risk. In the field of construction projects, the lack of precise information is associated with property investments because: 1) data are usually not readily available in consistent form; 2) the diversity among properties often resists analysis and interpretation of general trends; and 3) properties are place-bound, producing even greater uncertainty about the future prospects of a property than for other economic goods that can be moved (Bagnoli, Smith 1999). Therefore, using linguistic variables and respective fuzzy numbers to evaluate the factors, fuzzy set theory is highly appropriate to employ at the stage of price inference in a construction project.

Istanbul is the largest city in Turkey with more than 12 million official residences. With an area of $5,712 \mathrm{~km}^{2}$, Istanbul covers only $0.7 \%$ of Turkey; however, it holds more than $15 \%$ of the population within its geographic boundaries. Istanbul is declared as the number one among 27 European metropolitans for investment potential in real estate by PricewaterhouseCoopers $(\mathrm{PwC})$ and Urban Land Institute (ULI). Istanbul, commercial, financial \& cultural capital of Turkey, is located on the crossroads of Europe and Asia. The city accounts for 10\% of the housing gap in Turkey. The total market value of the 22 real estate investment companies publicly traded on the Istanbul Stock Exchange has reached 11.7 billion TL. According to the report prepared by EVA Real Estate Appraisal Consultancy (2011), 288,000 housings in Istanbul will be supplied for sale in 2012. The number of housings in Istanbul is expected to be 23 million in 2023. It is estimated that housing requirement due to population increase will be 900,000 units in 2017 (EVAGYD 2012). 
Fuzzy set theory has been widely applied in the industrial system controls that are very complex, uncertain and cannot be modelled precisely (Ustundag et al. 2011). Fuzziness is inherent in many problems of knowledge representation, and the other is that high-level managers or complex decision processes often deal with generalized concepts and linguistic expressions, which are generally fuzzy in nature. Fuzzy logic is capable of supporting to a reasonable extent, human type reasoning in natural form. Fuzzy rule based systems have been the most popular and easiest way to capture and represent fuzzy, vague, imprecise and uncertain domain knowledge. The fuzzy rule based systems (FRBS) uses fuzzy IF-THEN rules to determine a mapping from fuzzy sets in the input universe of discourse to fuzzy sets in the output universe of discourse based on fuzzy logic principles.

In this context, this paper contributes to the relevant literature by integrating fuzzy inference and optimization for the economic evaluation of residential projects to determine the allocation among different types of residences. The inspiration of this study is the need for economic assessment of residential projects under changing market as well as economic conditions. The proposed model is applied to a residential project in Istanbul to demonstrate its performance and practicality for real life problems. The optimal Net Present Values (NPVs) and allocation results for four types of residences are analyzed depending on different factor levels of total construction area, sales rate, and bank loan interest rate.

The rest of the paper is organized as follows. Section 1 reviews the relevant literature. Section 2 presents the proposed model. Section 3 describes the application of the model. Section 4 presents an experimental design with the analysis of decisive factors. Finally, the last section concludes.

\section{Literature review}

Since economic evaluation of construction projects has recently received an emerging attention under fuzzy environment, there is a growing literature on this subject. For example, Chen et al. (2010) attempted to develop an automatic expert model using an approach based on rule extraction that provides practitioners with a prediction tool for the hedging of financial risks through the use of derivatives. Sun et al. (2008) used fuzzy analytical hierarchy process (AHP) for the risk evaluation of residential real estate projects. A major advantage of this method is that it allows experts and engineers to express their opinions on project risk evaluation in linguistic variables rather than crisp values. Mao and Wu (2011) developed a financial risk assessment model for real estate investment that was based on fuzzy real option. A cash flow calculation methodology for projects including activities with fuzzy durations and costs was proposed by Maravas and Pantouvakis (2012). The authors represented the project cash flow by an S-surface at different risk possibility levels. The methodology was applied in working capital requirements estimation in a real-world road construction project. Kahraman and Kaya (2012) developed a fuzzy multiple attribute utility model for intelligent building assessment. The evaluation of three alternative intelligent buildings for a business center in Istanbul was performed within the application of their model.

Since, the proposed methodology includes a mixed integer linear programming model, it will be meaningful to review linear programming applications. In the context of linear programming (LP), the objective function should be a linear function of the decision variables. An LP will either minimize or maximize the value of the objective function. Finally, the decisions that must be made are subject to certain requirements and restrictions of a system which are called constraints (Smith, Taşkın 2008). LP has been widely used in optimizing complex systems, such as those arising in marketing (Stapleton et al. 2003), finance (Benati, Rizzi 2007), energy (Xydis, Koroneos 2012), product design (Seibi, Sawaqed 2002), transportation (Luathep et al. 2011), production planning and control (Rasmussen 2013; Doganis, Sarimveis 2007), chemistry (Rossi et al. 2009), medicine (Mangasarian et al. 1994), telecommunications (Sirdey, Maurice 2008), sports (Soleimani-Damaneh et al. 2011), and military (Tucker et al. 1998). Some attempts have been made to develop linear programming models for optimization problems in construction industry. In a recent study, Montemanni et al. (2012) used robust LP to produce solutions protected against noisy data with the same computational complexity of the classic optimization methods for the aggregate blending. The authors also showed that nonlinear cost functions can be approximated by piecewise linear functions, keeping complexity at a low level. Barbosa et al. (2001) proposed a LP model for optimal cash flow management addressing specific cash flow issues related to the construction industry. The model considers typical financial transactions, possible delays on payments, use of available credit lines, effect of changing interest rates, and budget constraints that often occur in the construction industry. As for the work force optimization aspect, Mohammadpour et al. (2008) combined training and hiring workforce in different levels of skills in their LP model. The input data consists of certain available labor pool, cost configures for training workforce in different skills, the cost of hiring workforce, hourly labor wages, and estimates of affinities among the different considered skills and their levels. Similarly, Srour et al. (2006) built Optimal Workforce Investment Model to provide an optimization-based framework for matching supply and demand of construction labor most efficiently through training, recruitment, and allocation. Li (2011) considered the risk estimation of the real estate development on the characters of the real estate and the function analysis of the residential real estate, then gives a decision analysis for one certain residential community based on the mathematic model of the multiobjective LP. Susilawati (1998) and attempted to determine 
the best combination of the type of single houses, shop houses and public facilities in a residential project with the aim of maximizing net present value of the project. However, the study has the limitation of neglecting current market conditions and the payment restructuring. Susilawati et al. (2001) determined the number of rooms and area of each facility which could satisfy the constraints and to obtain optimum profit in a dormitory construction project via LP. In addition, fuzzy parameters in LP are considered for profit maximization (Kumar et al. 2003) and equipment deployment (Eshwar et al. 2004) in construction projects.

Some efforts have been made to appraise real estates in fuzzy environment (Lughofer et al. 2011; Ustundag et al. 2011; Kusan et al. 2010). In an early study, Bagnoli and Smith (1999) applied fuzzy logic techniques in real estate valuation and obtained fuzzy set output in the end; however, they neglected risk factors. Cui and Hao (2006) studied the method of fuzzy mathematics into cost approach for real estate appraisal. Comparing similar properties with subject building to estimate the major consumption of materials and labor, the method determined the replacement cost at that time. Furthermore, this paper adopted analytical hierarchy process to estimate the depreciation of a building. Barranco et al. (2004) described a web-based application which took advantage of fuzzy sets to apply them on the area of real estate management. The paper showed the way real estate attributes could be expressed by using fuzzy data, and how fuzzy queries could be used to apply typical real estate customer requirements on a database. Krol et al. (2007) compared two fuzzy models for real estate appraisal - Mamdani-type and Takagi-Sugeno-Kang-type.
Liu et al. (2006) developed a fuzzy neural network prediction model based on hedonic price theory to estimate the appropriate price level for a new real estate.

Consideration of the relevant literature revealed that there has not been any published study which not only addressed the residence type allocation problem, but also considered factors affecting price under vagueness of data. In this context, this paper has the originality of presenting a net present value oriented optimization approach that includes a FRBS for residence type allocation problem to address this research gap.

\section{Proposed approach}

The flowchart which is followed within the proposed methodology is given in Figure 1.

The proposed model for financial assessment of residential projects consists of two phases. In the first phase, the inference of price per $\mathrm{m}^{2}$ is performed depending on home loan interest rate (HLIR), consumer confidence index $(C C I)$, and housing supply $(H S)$ in a Mamdani-type FRBS. The inputs of the FRBS are defined as follows:

- Home loan interest rate: It can be expressed as the interest rate for the loan gotten from a financial institution for home buying.

- Consumer confidence index: It is an indicator designed to measure consumer confidence, which is defined as the degree of optimism on the state of the economy that consumers are expressing through their activities of savings and spending.

- Housing supply: It can be denoted as the total number of houses (apartments, residences, etc.) available for sale at a time.

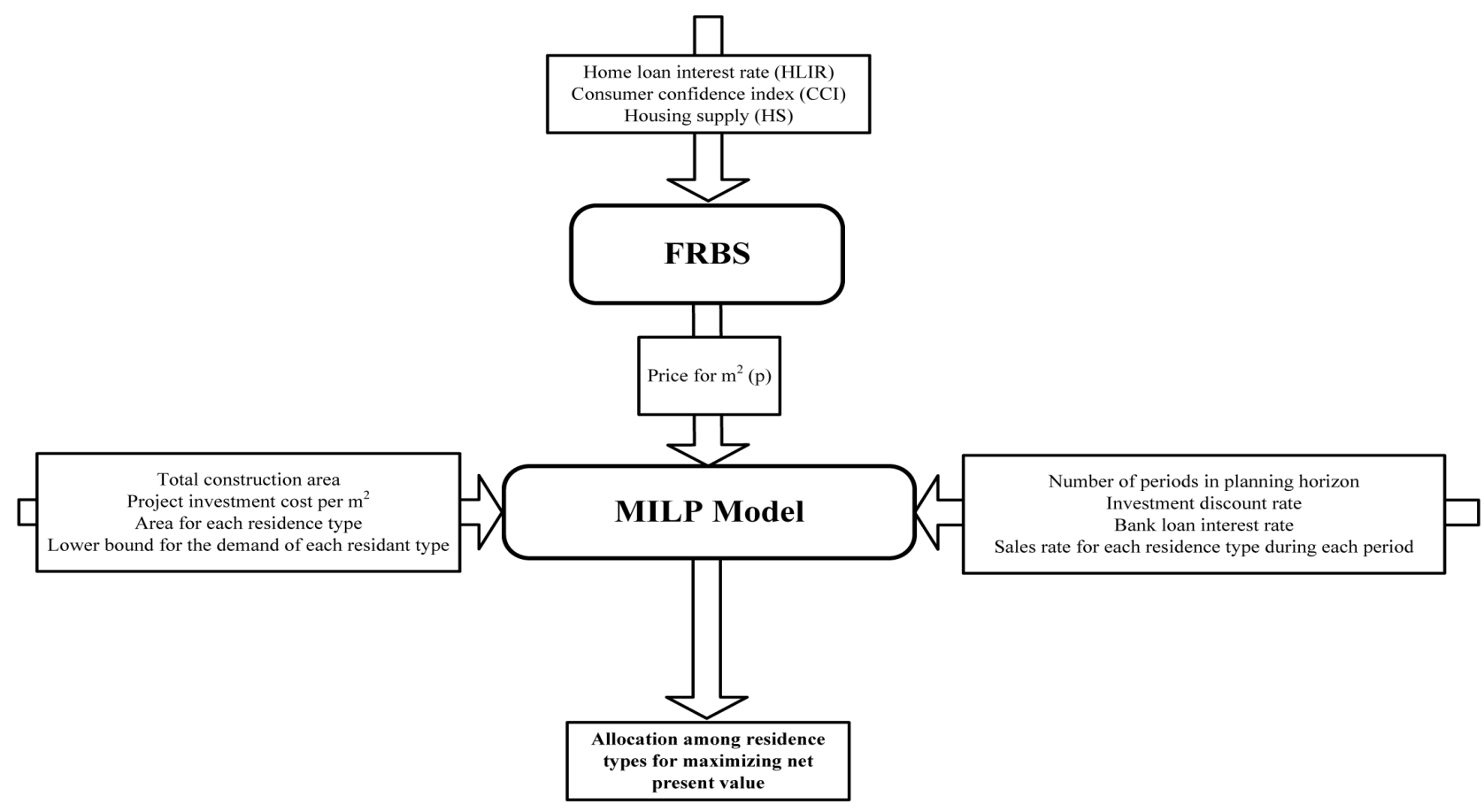

Fig. 1. Framework of the proposed approach 
The rule base constructed by the help of the real estate experts for determining the price for $\mathrm{m}^{2}$ of residences is as follows:

- IF HLIR is Low AND CCI is High AND HS is Low THEN $p$ is High.

- IF HLIR is Medium AND CCI is Medium AND HS is High $p$ is Low.

- IF HLIR is High AND CCI is Medium AND HS is Medium THEN $p$ is Low.

- IF HLIR is High AND CCI is Medium AND HS is Low THEN $p$ is Medium.

- IF HLIR is Medium AND CCI is Low AND HS is Medium THEN $p$ is Low.

Then, the output of FRBS (i.e. price per $\mathrm{m}^{2}$ ) is considered as an input for the mixed integer linear programming (MILP) model in the second phase of the proposed approach.

The proposed MILP model determines the allocation of total construction area among different types of residences such that NPV of the project is maximized. In the MILP model, NPV is based on cost and benefit values of the project during the periods of the planning horizon with respect to investment discount rate. Benefits of the project is related with sales rate for each residence type during each period, price per $\mathrm{m}^{2}$ as the parameters and the number of constructed residences for each type as the variable. Total construction cost and financing cost constitute the total cost of the project. Total construction area and investment cost per $\mathrm{m}^{2}$ are handled to obtain total construction cost. Financial cost on the basis of each period is related with bank loan interest rate. In addition, it is considered that payments are restructured according to the payments of the project's owner. Project's owner decides minimum quantity for each resident type according to his/her experience. This point is reflected to the model as a constraint related with lower bound for the demand of each resident type as a parameter. The parameter of total construction area is considered as another constraint when the area and the number of constructed residences for each residence type are considered as parameter and variable, respectively.

The formulation and detailed information about the MILP model are presented as follows.

\section{Indices}

$i$ : Index for residence type;

$h$ : Index for residence type;

$j$ : Index for period.

\section{Parameters}

$I=$ The number of residence types;

$J=$ The number of periods in planning horizon;

$d=$ Investment discount rate;

$k=$ Bank loan interest rate;

$C=$ Total construction area;

$b=$ Project investment cost per $\mathrm{m}^{2}$;

$T B=$ Total project investment cost;

$$
T B=C * b ;
$$

$M_{i}=$ Area for residence type $i$;

$Q_{i}=$ Lower bound for the construction of residence type for $i=1, \ldots, I$;

$r_{i j}=$ Sales rate for each residence type $i$ during period for $i=1, \ldots ., I ; \quad j=1, \ldots ., J$;

$p=$ price per $\mathrm{m}^{2}$;

$P_{i}=$ Price for residence type $i \quad$ for $i=1, \ldots, I$;

$$
P_{i}=M_{i} * p \quad \text { for } i=1, \ldots, I
$$

$M=$ A large positive number;

$a_{h}=$ Coefficient identifying the necessary condition between two resident types.

In the parameter section above, Eqn (1) calculates the total project investment cost and Eqn (2) determines the price for each type of residence.

\section{Variables}

for $i=1, \ldots ., I \quad j=1, \ldots ., J$;

$B_{j}=$ Loan payment amount (principal + interest) at period $j$;

$A_{j}=$ Principal payment amount at period $j$;

$S_{j}=$ Total revenue obtained from residence sales at period $j$;

$G_{j}=$ The remaining revenue after loan payment at period $j$;

$N_{j}=$ The remaining revenue after paying towards the principal at period $j$;

$T B_{j}=$ The remaining total loan payment amount as of the period $j$;

$L_{j}=$ The remaining total principal amount to be paid as of the period $j$;

$x_{i j}=$ The number of type $i$ of residence at the period $j$.

Objective function:

$$
\operatorname{Maximize} \sum_{j=1}^{J} \frac{N_{j}}{(1+d)^{j}} .
$$

Objective function (3) maximizes the net present value of the project depending on the investment discount rate in the planning horizon.

Subject to:

$$
S_{j}=\sum_{i=1}^{I} P * r_{i j} * x_{i j}, j=1, \ldots ., J .
$$

Constraint (4) determines the total revenue obtained from residence sales for each period based on price and sales rate for each residence type:

$$
B_{j}=\frac{T B_{j}(1+k)^{(J-j+1)}}{(J-j+1)}, j=1, \ldots ., J .
$$

Constraint (5) defines the total loan payment amount for each period with respect to bank loan rate:

$$
A_{j}=\frac{T B_{j}}{(J-j+1)}, \quad j=1, \ldots ., J .
$$


Constraint (6) identifies the principal payment amount for each period:

$$
G_{j}=S_{j}-B_{j}, \quad j=1, \ldots ., J .
$$

Constraint (7) defines the remaining revenue after loan payment at each period:

$$
L_{j}=T B_{j}-A_{j}, \quad j=1, \ldots ., J-1 ;
$$

Constraint (8) specifies the remaining total principal amount to be paid as of period $j$ :

$$
\begin{aligned}
& T B_{j+1} \geq L_{j}-G_{j} \quad j=1, \ldots ., J-1 ; \\
& T B_{j+1} \geq 0 \quad j=1, \ldots ., J-1 ; \\
& T B_{j+1}-L_{j}+G_{j} \leq M * y_{j} \quad j=1, \ldots ., J-1 ;(9 \mathrm{c}) \\
& L_{j}-G_{j} \leq M *\left(1-y_{j}\right) \quad j=1, \ldots . ., J \\
& T B_{j+1} \leq \mathrm{M} * z_{\mathrm{j}} \quad j=1, \ldots ., J-1 ; \\
& G_{j}-L_{j} \leq M *\left(1-z_{j}\right) \quad j=1, \ldots ., J \\
& T B_{j+1} \leq M * w_{j} \quad j=1, \ldots ., J-1 ; \\
& T B_{j+1}-L_{j}+G_{j} \leq \mathrm{M} * w_{\mathrm{j}} \quad j=1, \ldots ., J-1 \\
& N_{j} \geq G_{j}-L_{j} \quad j=1, \ldots, J \\
& N_{j} \geq 0 \quad j=1, \ldots, J \\
& N_{j} \leq M * y_{j}^{\prime} \quad j=1, \ldots, J \\
& L_{j}-G_{j} \leq M *\left(1-y_{j}^{\prime}\right) \quad j=1, \ldots . ., J \\
& N_{j}+L_{j}-G_{j} \leq M * z^{\prime}{ }_{j} \quad j=1, \ldots ., J \\
& G_{j}-L_{j} \leq M *\left(1-z_{j}^{\prime}\right) \quad j=1, \ldots, J \\
& N_{j} \leq M * w_{j}^{\prime} \quad j=1, \ldots, J \\
& N_{j}+L_{j}-G_{j} \leq M *\left(1-w_{j}^{\prime}\right) \quad j=1, \ldots, J .
\end{aligned}
$$

Constraints (9) and (10) provide that the construction project's owner makes extra payments towards the principle and lowers his bank loan and interest in case of a positive cash flow. Constraint set (9) equalizes $T B_{j+1}$ to $\left(L_{j}-G_{j}\right)$ on the condition that $G_{j}$ is smaller than $L_{j}$. Otherwise, $T B_{j+1}$ takes the value of 0 . If $G_{j}$ is greater than $L_{j}$, constraint set (10) makes $N_{j}$ equal to $\left(G_{j}-L_{j}\right)$. Otherwise, 0 is assigned as the value of $N_{j}$ :

$$
\sum_{i=1}^{I} \sum_{j=1}^{J} M_{i} * x_{i j} \leq C .
$$

Constraint (11) implies that the sum of the area for residences supplied is limited to total construction area:

$$
\sum_{j=1}^{J} x_{i j} \geq Q_{i}, \quad i=1, \ldots ., I .
$$

Constraint (12) assures that the supply of each residence type exceeds its related lower bound value in terms of the number of residences:

$$
\sum_{j=1}^{J} x_{i j} \geq a_{h} \sum_{j=1}^{J} x_{h j}, i=1, \ldots ., I ; h=1, \ldots ., I i \neq h .
$$

Constraint (13) identifies the necessary conditions between two residence types which should be met:

$$
\begin{array}{r}
B_{j}, A_{j}, F_{j}, S_{j}, G_{j}, N_{j}, T B_{j}, L_{j} \geq 0, \quad j=1, \ldots ., J \\
x_{i j} \geq 0 \text { and integer } i=1, \ldots ., I, \quad j=1, \ldots ., J ; \\
y_{j}, z_{j}, w_{j}, y_{j}^{\prime}, z_{j}^{\prime}, w_{j}^{\prime} \in[0,1] \text { and integer. }
\end{array}
$$

Constraint set (14) defines the domains for variables.

\section{Application}

In this study, a residential project investment in Istanbul is evaluated by determining the optimized allocation of residence types to maximize the Net Present Value (NPV). The project has four types of residences with different number of rooms and floor area as shown in Table 1.

In this application, the project investment cost is covered by a bank loan. The payment period is five years and it is paid in equal yearly instalments with a fixed interest rate of $8 \%$. Total construction area is $25,000 \mathrm{~m}^{2}$ and the project investment cost per square meter is assumed as $\$ 600$. The

Table 1. Residence types

\begin{tabular}{lcc}
\hline Residence Type & Number of rooms & Area $\left(\mathrm{m}^{2}\right)$ \\
\hline 1 & $1+1$ & 60 \\
\hline 2 & $2+1$ & 90 \\
\hline 3 & $3+1$ & 140 \\
\hline 4 & $4+1$ & 190 \\
\hline
\end{tabular}


Table 2. Sales rate for each year

\begin{tabular}{cc}
\hline Year & Sales Rate \\
\hline 1 & $10 \%$ \\
\hline 2 & $10 \%$ \\
\hline 3 & $10 \%$ \\
\hline 4 & $35 \%$ \\
\hline 5 & $35 \%$ \\
\hline
\end{tabular}

sales rate for each year is given in Table 2. It is assumed that each residence type has the same sales rate and all the residences will be sold at the end of the fifth year.

If the construction project's owner has positive cash flow at the end of the each year, then he makes extra payments towards the principle and lowers the yearly paid bank loan and interest amount.

According to the proposed hybrid approach, in the first phase, FRBS is used to provide price per $\mathrm{m}^{2}$ and provides input for NPV formulation. Table 3 presents the linguistic variables and the corresponding fuzzy numbers used in FRBS.

The FRBS model is solved using the Matlab Fuzzy Logic ToolBox and the price per $\mathrm{m}^{2}$ is obtained as $\$ 2,000$ given the values of HLIR, CCI and $H S$ as 1.15, 95 and 600 respectively.

In the second phase, mixed integer linear programming (MILP) model is used to determine the optimal numbers of residence types to maximize the NPV of the project. The discount rate is assumed as $6 \%$ when calculating the NPV of the project. In the model, in Eqn (12), the lower bound of the number of a residence type is determined $5 \%$ of possible maximum number of this residence type. In this application, the construction project's owner stated that the number of residences of type 2 and type 3 should be 1.5 times greater than that of residences of type 1 and type 4 . He also decided that the number of residences of type 3 should be greater than that of residences of type 2 . Additionally, the number of residences of type 1 should be 4 times less than that of residences

Table 3. Linguistic variables

\begin{tabular}{llc}
\hline \multirow{2}{*}{ HLIR } & \multicolumn{1}{c}{ Scale } & $\begin{array}{c}\text { Corresponding Fuzzy } \\
\text { Numbers }\end{array}$ \\
\hline \multirow{3}{*}{ CCI } & Low & $(0.8,0.9,1)$ \\
\cline { 2 - 3 } & Medium & $(0.9,1,1.3)$ \\
\cline { 2 - 3 } & High & $(1.2,1.4,1.5)$ \\
\hline \multirow{3}{*}{ HS } & Low & $(75,80,85)$ \\
\cline { 2 - 3 } & Medium & $(80,85,90)$ \\
\cline { 2 - 3 } & High & $(500,600,650)$ \\
\hline \multirow{2}{*}{$\mathrm{p}$} & Low & $(700,900,700,800)$ \\
\cline { 2 - 3 } & Medium & $(1500,1800,2000)$ \\
\cline { 2 - 3 } & High & $(1800,2000,2500)$ \\
\hline & Low & Medium
\end{tabular}

of type 4. All these statements are included in the model using Eqn (13).

In this study, MILP model is solved using FICO Xpress Optimization Suite. Given the values above, the maximized NPV is calculated as $\$ 25,875,150$ for a fiveyear planning horizon determining the optimal numbers of residences as $46,76,76$, and 25 for type $1,2,3$, and 4 , respectively.

\section{Experimental design and analysis}

In this section, an experimental design is conducted for the above application using total construction area, sales rate, and bank loan interest rate in five levels given in Tables 4 and 5 as main factors. The optimal NPVs and allocation results for residences are analyzed depending on different factor levels. For the analysis, $125(5 \times 5 \times 5)$ experiments are conducted, and the impact of the designated factors on the NPVs and allocation results are investigated.

As seen in Figure 2, the NPV of the investment project increases as the size of the construction area increases. The average NPV increases from \$28 Million to $\$ 133$ Million when the construction area increases from $25,000 \mathrm{~m}^{2}$ to $125,000 \mathrm{~m}^{2}$. Hence, it can be stated that there is a positive linear relation between construction area and NPV. Additionally, construction area has a considerable impact on NPV. Figure 2 also indicates that the rising level of sales rate enhances the rate of increase of NPV depending on the construction area.

In Figure 3, the results point out that the NPV of the investment project is slightly decreasing with the rising level of the bank loan interest rate. It can also be stated that the decrease rate of NPV is lowering with the increasing level of bank loan interest rate since the construction project owner's extra payments towards the principle lowers the yearly paid bank loan amount much more at higher level of interest rate.

In addition to all these, ANOVA, the specified statistical technique, is conducted to determine whether the increase of independent factors' values has an impact on NPV of the investment project using IBM SPSS Statistics 20 software. According to Table 6 , the $p$-value for total construction area is lower than 0.05; thus, there is a significant difference between factor levels. However, a similar interpretation cannot be made for the other independent factors, sales rate and bank loan interest rate; there is not a significant difference between different groups.

Table 4. Sales rate for each period

\begin{tabular}{lccccc}
\hline Year & $\begin{array}{l}\text { Very_ } \\
\text { Slow }\end{array}$ & Slow & Moderate & Fast & Very_Fast \\
\hline 1 & $10 \%$ & $10 \%$ & $10 \%$ & $35 \%$ & $60 \%$ \\
\hline 2 & $10 \%$ & $10 \%$ & $35 \%$ & $35 \%$ & $10 \%$ \\
\hline 3 & $10 \%$ & $35 \%$ & $35 \%$ & $10 \%$ & $10 \%$ \\
\hline 4 & $35 \%$ & $35 \%$ & $10 \%$ & $10 \%$ & $10 \%$ \\
\hline 5 & $35 \%$ & $10 \%$ & $10 \%$ & $10 \%$ & $10 \%$ \\
\hline
\end{tabular}


Table 5. Factor levels for experimental design

\begin{tabular}{lccccc}
\hline \multicolumn{1}{c}{ Factors } & Level 1 & Level 2 & Level 3 & Level 4 & Level 5 \\
\hline $\begin{array}{l}\text { Total construction } \\
\text { area }\left(\mathrm{m}^{2}\right)(C)\end{array}$ & 25,000 & 50,000 & 75,000 & 100,000 & 125,000 \\
\hline Sales rate $(r)$ & Very slow & Slow & Moderate & Fast & Very fast \\
\hline $\begin{array}{l}\text { Bank loan interest } \\
\text { rate }(k)\end{array}$ & $8 \%$ & $9 \%$ & $10 \%$ & $11 \%$ & $12 \%$ \\
\hline
\end{tabular}

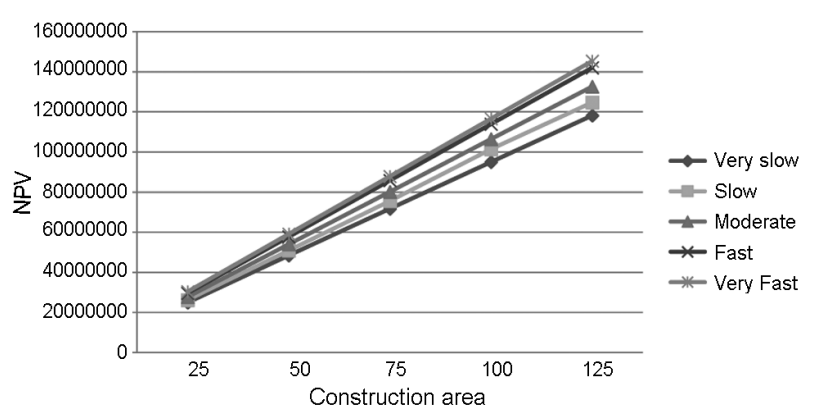

Fig. 2. NPV of the investment project depending on $C$ and $r$

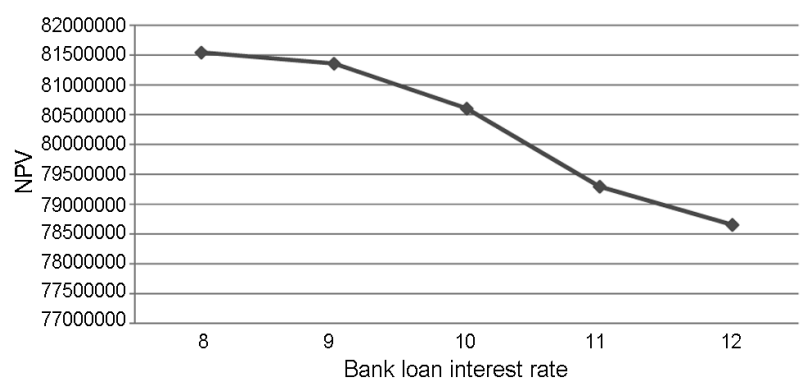

Fig. 3. NPV of the investment project depending on $k$

Table 6. ANOVA for NPV

\begin{tabular}{lcc}
\hline \multirow{2}{*}{ Independent Variable: } & \multicolumn{2}{c}{ Dependent Variable: NPV } \\
\cline { 2 - 3 } & $\mathrm{F}$ & Sig. \\
\hline $\begin{array}{l}\text { Total construction } \\
\text { area }\end{array}$ & 856,892 & $.000^{*}$ \\
\hline Sales rate & 0.793 & 0.532 \\
\hline $\begin{array}{l}\text { Bank loan interest } \\
\text { rate }\end{array}$ & 0.027 & 0.999 \\
\hline
\end{tabular}

In this study, the impact of designated independent factors on the number of residences of different types is also investigated. In Figure 4, the results show that increasing loan interest rate does not change the optimal number of residences of different types. The average number of residences for type 1, 2, 3, and 4 are determined as 93, 221, 233, and 85, respectively.

In Figure 5, the results show that the increasing sales rate also doesn't change the optimized number of residences of different types with the exception of Type 2 at very fast level. The average number of residences for type 1, 2, 3 and 4 are also determined as 93, 221, 233 and 85 respectively.

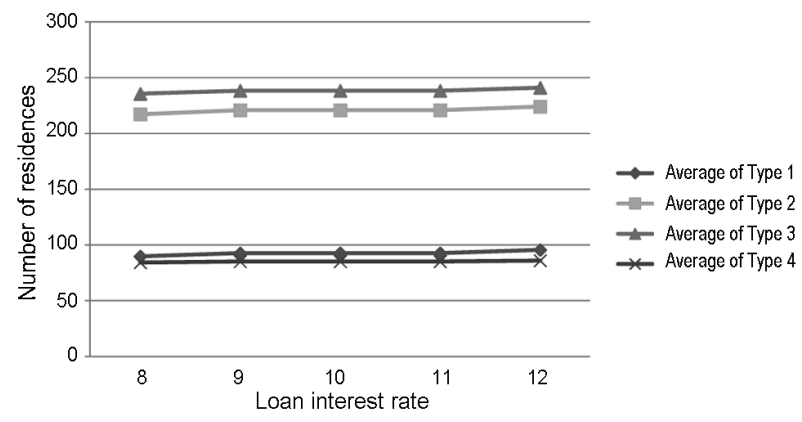

Fig. 4. Number of residences of the investment project depending on $k$

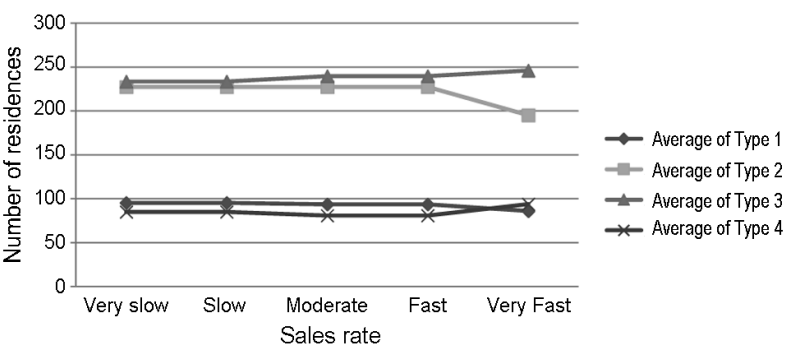

Fig. 5. Number of residences of the investment project depending on $r$

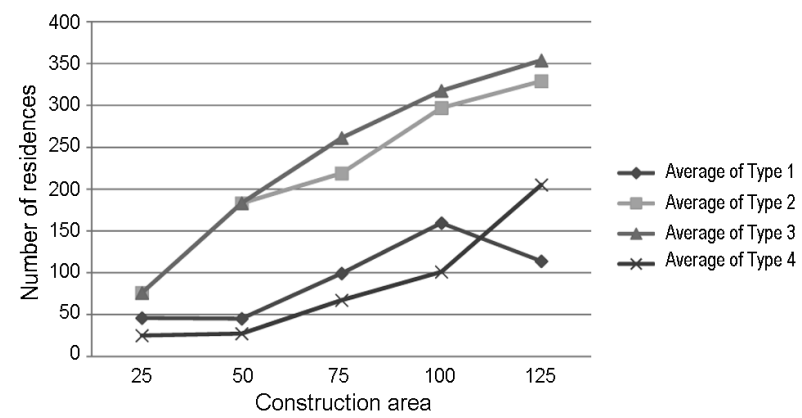

Fig. 6. Number of residences of the investment project depending on $C$

In Figure 6, the results show that an incline in construction area leads to an increase in the optimal number of residences of different types. According to ANOVA results presented in Table 7 , the $p$-value for total construction area is lower than 0.05; thus, there is a significant difference between different types of residences. 
Table 7. ANOVA for number of residences

\begin{tabular}{lcc}
\hline Dependent Variable: & \multicolumn{2}{c}{$\begin{array}{c}\text { Independent Variable: } \\
\text { Construction area }\end{array}$} \\
\cline { 2 - 3 } & $\mathrm{F}$ & Sig. \\
\hline Tymeer of residences 1 & 1659 & $.000^{*}$ \\
\hline Type 2 & 394 & $.000^{*}$ \\
\hline Type 3 & 1140 & $.000^{*}$ \\
\hline Type 4 & 2417 & $.000^{*}$ \\
\hline
\end{tabular}

\section{Conclusions}

The financial assessment of construction projects is a complex problem in free market economies. Even in wellorganized and relatively efficient markets, the net present values of the construction investment projects are difficult to estimate since several economic factors have influence on factors such as sales price, sales amount, discount rate, loan interest rate, etc. In this study, a framework for financial assessment of construction projects is proposed. Providing optimal allocation among residence types with respect to net present value singles the proposed study out in the relevant literature. This study has the potential to provide a convenience financial control for construction project owner via the integration of FRBS and MILP.

The case study demonstrated the applicability of the model when determining the net present value of the project. An experimental design is also conducted using the factors of total construction area, sales rate, and bank loan interest rate. The optimal NPVs and allocation results for four types of residences are analyzed depending on different factor levels. The results indicate that the factor of construction area has a considerable impact on NPV. So, there is a positive relationship between them. Additionally, the rising level of construction area influences the allocation of different types of residences, so it increases the number of residences with higher unit prices considering the necessary conditions between two types of residences. Since this factor has an impact on the total sales revenue, it also influences the optimal allocation of residences. The rising level of sales rate influence the optimal NPV but does not have any impact on the allocation of different types of residences. The higher level of sales rate provides that the construction project's owner makes more extra payments towards the principle and lowers his bank loan faster, so the optimal NPV is increased. However, the allocation of different types of residences doesn't change since the total sales revenue remains stable. Additionally, the results point out that the rising level of bank loan interest rate decreases the optimal NPV, since it increases the total amount of interest paid by the construction project's owner. However, the rising level of bank loan interest rate doesn't influence the allocation of different types of residences similar to the sales rate factor since the total sales revenue doesn't change. In summary, the results indicate that the allocation of different types of residences is only influenced by the factor of construction area. However, the optimal NPV is influenced by the three factors.

There are several avenues for future research. First of all, MILP model can be modified for fuzzy parameters. Then, the approach can be adapted for different types of construction projects. Finally, different comfort levels can be considered in MILP.

\section{References}

Bagnoli, C.; Smith, H. C. 1999. The theory of fuzzy logic and its application to real estate valuation, Journal of Real Estate Research 16(2): 169-199.

Barbosa, P. S. F.; Pimentel, P. R. 2001. A linear programming model for cash flow management in the Brazilian construction industry, Construction Management and Economics 19(5): 469-479.

http://dx.doi.org/10.1080/01446193.2001.9709623

Barranco, C. D.; Campria, J.; Medina, J. M.; Pons, O. 2004. Immosoftweb: a web based fuzzy application for real estate management, Lecture Notes in Artificial Intelligence 3034: 196-206.

Benati, S.; Rizzi, R. 2007. Mixed integer linear programming formulation of the optimal mean/Value-at-Risk portfolio problem, European Journal of Operational Research 176(1): 423-434. http://dx.doi.org/10.1016/j.ejor.2005.07.020

Chen, J. H.; Yang, L. R.; Su, M. C.; Lin, J. Z. 2010. A rule extraction based approach in predicting derivative use for financial risk hedging by construction companies, Expert Systems with Applications 37(9): 6510-6514. http://dx.doi.org/10.1016/j.eswa.2010.02.135

Cui, P. P.; Hao, S. Y. 2006. The study on cost approach in real estate appraisal based on fuzzy mathematics, in The CRIOCM 2006 International Symposium on Advancement of Construction Management and Real Estate [online], [cited 20 March 2012]. Available from Internet: http://www.irbdirekt.de/daten/iconda/CIB5724.pdf

Doganis, P.; Sarimveis, H. 2007. Optimal scheduling in a yogurt production line based on mixed integer linear programming, Journal of Food Engineering 80(2): 445-453. http://dx.doi.org/10.1016/j.jfoodeng.2006.04.062

Eshwar, K.; Kumar, V. S. S. 2004. Optimal deployment of construction equipment using linear programming with fuzzy coefficients, Advances in Engineering Software 35(1): 27-33. http://dx.doi.org/10.1016/S0965-9978(03)00111-X

EVAGYD. 2012. Istanbul Real Estate Market [online], [cited 25 April 2012]. Available from Internet: http://www.evagyd.com

Eva Real Estate Appraisal Consultancy. 2011. Istanbul Real Estate Sector Report 2011. 5 p.

Kahraman, C.; Kaya, I. 2012. A fuzzy multiple attribute utility model for intelligent building assessment, Journal of Civil Engineering and Management 18(6): 811-820. http://dx.doi.org/10.3846/13923730.2012.720932

Krol, D.; Lasota, T.; Trawinski, B.; Trawinski, K. 2007. Comparison of Mamdani and TSK fuzzy models for real estate appraisal lecture notes in computer science, KnowledgeBased Intelligent Information and Engineering Systems 4694(2007): 1008-1015. http://dx.doi.org/10.1007/978-3-540-74829-8_123

Kumar, V. S. S.; Hanna, A. S.; Natarajan, P. 2003. Application of fuzzy linear programming in construction projects, International Journal of IT in Architecture, Engineering and Construction 1(4): 265-274.

Kusan, H.; Aytekin, O.; Özdemir, I. 2010. The use of fuzzy logic in predicting house selling price, Expert Systems with Applications 37(3): 1808-1813. http://dx.doi.org/10.1016/j.eswa.2009.07.031 
Li, X. 2011. The analysis on residential real estate development multi-objective linear programming and decision, in Proceedings in $2^{\text {nd }}$ International Conference on Artificial Intelligence, Management Science and Electronic Commerce, 8-10 August 2011, Deng Feng, China, $1620-1623$.

Liu, J. G.; Zhang, X. L.; Wu, W. P. 2006. Application of fuzzy neural network for real estate prediction, Lecture Notes in Computer Science, Advances in Neural Networks 3973: 1167-1191.

Luathep, P.; Sumalee, A.; Lam, W. H. K.; Li, Z.-C.; Lo, H. K. 2011. Global optimization method for mixed transportation network design problem: a mixed-integer linear programming approach, Transportation Research Part B: Methodological 45(5): 808-827.

http://dx.doi.org/10.1016/j.trb.2011.02.002

Lughofer, E.; Trawinski, B.; Trawinski, K.; Kempa, O.; Lasota, T. 2011. On employing fuzzy modeling algorithms for the valuation of residential premises, Information Sciences 181(23): 5123-5142. http://dx.doi.org/10.1016/j.ins.2011.07.012

Mangasarian, O. L.; Street, W. N.; Wolberg, W. H. 1994. Breast cancer diagnosis and prognosis via linear programming, Mathematical Programming Technical Report 94(10): 1-9.

Mao, Y.; Wu, W. 2011. Fuzzy real option evaluation of real estate project based on risk analysis, Systems Engineering Procedia 1: 228-235. http://dx.doi.org/10.1016/j.sepro.2011.08.036

Maravas, A.; Pantouvakis, J. P. 2012. Project cash flow analysis in the presence of uncertainty in activity duration and cost, International Journal of Project Management 30(3): 374384. http://dx.doi.org/10.1016/j.ijproman.2011.08.005

Mohammadpour, A.; Khanzadi, M.; Eshtehardian, E. 2008. Linear programming for optimizing strategic construction workforce management, in Proceedings in First International Conference on Construction in Developing Countries, 4-5 August 2008, Karachi, Pakistan, 161-167.

Montemanni, R.; Toklu, N. E.; Toklu Y. C.; Toklu, Y. C. 2012. Aggregate blending via robust linear programming, Journal of Construction Engineering and Management 138(2): 188-196.

http://dx.doi.org/10.1061/(ASCE)CO.1943-7862.0000422

Rasmussen, S. 2013. Use of linear programming in practical production planning, in Springer texts in business and economics. Berlin Heidelberg: Springer-Verlag, 235-267.

Rossi, C. C. R. S.; Cardozo-Filho, L.; Guirardello, R. 2009. Gibbs free energy minimization for the calculation of chemical and phase equilibrium using linear programming, Fluid Phase Equilibria 278(1-2): 117-128. http://dx.doi.org/10.1016/j.fluid.2009.01.007

Seibi, A. C.; Sawaqed, N. M. 2002. Design of copper filled fibreglass moulds for manufacturing a customized product using linear programming optimization and finite element analysis, Composites Part A: Applied Science and Manufacturing 33(12): 1677-1683.

http://dx.doi.org/10.1016/S1359-835X(02)00186-0

Sirdey, R.; Maurice, F. 2008. A linear programming approach to highly precise clock synchronization over a packet network, 4OR 6(4): 393-401.

http://dx.doi.org/10.1007/s10288-007-0060-6

Smith, J. C.; Taşkın, Z. C. 2008. A tutorial guide to mixedinteger programming models and solution techniques, in Optimization in Medicine and Biology. Auerbach Publications, 1-23. http://dx.doi.org/10.1201/9780849305696.axa

Soleimani-Damaneh, J.; Hamidi, M.; Sajadi, N. 2011. Evaluating the performance of Iranian football teams utilizing linear programming, American Journal of Operations Research 1: 65-72. http://dx.doi.org/10.4236/ajor.2011.12010

Srour, I. M.; Haas, C. T.; Morton, D. P. 2006. Linear programming approach to optimize strategic investment in the construction workforce, Journal of Construction Engineering and Management 132: 1158-1166.

http://dx.doi.org/10.1061/(ASCE)0733-9364(2006)132: 11(1158)

Stapleton, D. M.; Hanna, J. B.; Markussen, D. 2003. Marketing strategy optimization: using linear programming to establish an optimal marketing mixture, American Business Review 21(2): 54-62.

Sun, Y.; Huang, R.; Chen, D.; Li, H. 2008. Fuzzy set-based risk evaluation model for real estate projects, Tsinghua Science and Technology 13(S1): 158-164. http://dx.doi.org/10.1016/S1007-0214(08)70143-3

Susilawati, C. 1998. Optimal residential property development and linear programming, in Proceedings of $4^{\text {th }}$ Pacific Rim Real Estate Society Conference, 19-21 January 1998, Perth, Australia, 1-14.

Susilawati, C.; Litaay, D. L.; Parsaulian, A. 2001. Application of linear programming for dormitory development plan at Petra Christian Unıversity, Dimensi Teknik Sipil 3(2): 59-63.

Tucker, J. L.; Rideout, D. B.; Robert B.; Shaw, R. B. 1998. Using linear programming, in to optimize rehabilitation and restoration of injured land: an application to US army training sites, Journal of Environmental Management 52(2): 173-182. http://dx.doi.org/10.1006/jema.1997.0166

Ustundag, A.; Cevikcan, E.; Kilinc, M. S. 2011. A hybrid fuzzy risk evaluation model for real estate investments, Journal of Multiple-Valued Logic and Soft Computing 17: 339-362.

Xydis, G.; Koroneos, C. 2012 A linear programming approach for the optimal planning of a future energy system. Potential contribution of energy recovery from municipal solid wastes, Renewable and Sustainable Energy Review 16(1): 369-378. http://dx.doi.org/10.1016/j.rser.2011.08.001

Alp USTUNDAG. Associate Professor at Industrial Engineering Department in Istanbul Technical University (ITU). He has conducted research studies at Logistics Department of Dortmund University, Germany in 2007. He worked in IT and the finance industry from 2000 to 2004 . He has conducted a lot of research and consulting projects in reengineering, logistics and supply chain management for major Turkish companies. He is currently a Lecturer at Industrial Engineering Department in ITU. His current research interests include RFID, supply chain management, risk management, soft computing and optimization. He has published many papers in international journals and presented various studies at national and international conferences.

Emre CEVIKCAN. Assistant Professor at Industrial Engineering Department in Istanbul Technical University (ITU). He received the BS degree in Industrial Engineering from Y1ldz Technical University, the MSc degree and PhD degree in Industrial Engineering from Istanbul Technical University. He studied the scheduling of production systems for his $\mathrm{PhD}$ dissertation. He is currently a Lecturer in the Industrial Engineering Department of Istanbul Technical University. His research has so far focused on the design of production systems, lean production, scheduling. He has several research papers in international journals. 